\title{
THE ECONOMICS OF BEING STUPID: A NOTE ON (IR)RATIONALITY IN ECONOMICS
}

\section{Dan Štastný}

\section{Introduction}

Invoking the issue of rationality in economics is just about as intellectually unique, novel and exciting as an attempt to discover the real message of Keynes's General Theory. For many economists, and - frankly - one cannot blame them, the rationality assumption is a trite question that warrants almost no attention. To compensate for that, one cannot help but to use a pretentious title.

In the following text, I acknowledge the importance of rationality assumption for any economic theorizing, but propose that economists, in an attempt at explaining a seemingly irrational behavior in rational terms, are often engaging in a scientifically not very useful logical exercise. I follow some typical examples of such solutions and present a micro-survey to illustrate their possible inapplicability. I then argue that this state of affairs is caused by, and further contributes to, a neglect of the possibility of irrational behavior, and conclude by emphasizing the importance of allowing the possibility of folly.

Lest the purpose of this article be misunderstood, it is not concerned with the precise meaning or content of the rationality assumption (as e.g. Sen does [15]), neither does it criticize the employment of such assumption in economic theorizing. It rather belongs to a tradition of articles reminding us about deviations of fleshand-blood economic agents from the homo oeconomicus model - a tradition made wide, long and veritable by Kahneman (see e.g. [9]) and others. My aspiration within this tradition is modest at best: to point to a possible methodological slip in the way economist explicate certain phenomena and the economic consequences of it.

\section{The Rationality Assumption}

Economics, it is widely granted, is a science about the way people make choices and about consequences of such choices (e.g. [10]). Any decision, as opposed to non-volitional behavior, implies a use of reason to juxtapose the pros and cons of a given route of conduct. This, however, does not mean that one's reasoning must necessarily be at all times correct. The decision-maker may use all his reason, and yet his decision may nonetheless turn out wrong both ex ante and ex post.

One commonly acknowledged source of such errors is uncertainty. Due to necessarily imperfect knowledge of the present and future states of the world, every decision is based on expectations and these may prove wrong, thus making the decision - one that seemed perfectly correct ex ante - erroneous ex post.

There is, however, a different cause of error. Even if one correctly perceives both present and future states of the world (i.e. his expectation will match reality), a decision can still be wrong due to the individual being fundamentally mistaken about the means proper for the achievement of his ends (i.e. about causal relations between different states). His reason may well be telling him that certain means will lead to the desired ends, and thus his decision is conscious and thoughtful, and - no doubt - perceived by the decisionmaker as rational. Yet, he may be mistaken, confused or simply wrong about a particular means-ends relationship. This is the kind of situation that economists have in mind when they proclaim a behavior irrational - wrong from the very beginning, even ex ante. And, perhaps, this is precisely such behavior that other people would vernacularly call stupid. 
Even though economists recognize the possibility that people can make errors, most of them prefer to interpret human behavior in rational - error-free - terms. There is a very good reason for doing so. Invoking the possibility of error is a trivial explanation theoretically applicable in virtually all cases. It is an antiscientific solution, an answer requiring and producing no useful knowledge whatsoever. To any question, "Why is he doing that?", the universally correct answer may be that "He is just being stupid!"

The idea of rationality is then an overly important one for economics, at least for its main stream. Not because economists could not fathom an irrational decision, but because it is a starting point for what economists do: adding to trivial explanations of phenomena some non-trivial ones. Thus, without the concept of rationality there would be no science of economics.

On the other hand, it would be mistaken to suppose that economics is applicable only to situations where people do indeed act rationally, while having nothing to say about cases of people acting erroneously. First, thanks to economics, we are often able to suggest something about the rationality of the choice in the first place: without economics we would not be able to tell a rational from an irrational one. This is what economists do when they claim that $A$ is not a means that leads to the achievement of the end B. Second, economics being the science about consequences of human decisions, it can point out consequences of irrational behavior too. It can claim not only that $A$ does not lead to $B$, but that in fact it leads to $C$. And that too is a useful knowledge. Therefore, the presence of irrationality in human decision making does not strip economics of its usefulness and importance. The rationality assumption only enables economists to say much more than they would be able to without it.

\section{The Quest for Rational Interpretation: Rational Riddles}

Attempts to find rational explanation for human behavior have long been part of good economics and the provided explanations are arguably one of the most impressive kinds of economics' output for laymen and the most enjoyable ones to economists themselves. In the absence of a straightforward maximizing explanation, one can talk about rational riddles, a term coined by Landsburg [10, chapter 2].

However, in this quest for rational explanations, some economists seem to go as far as to implicitly assume that there must be a rational explanation of every human behavior we observe and they devote great time and energy towards discovering it. In this way, an economic, or rational, riddle was born and it remains to be economists' pastime agenda something to talk about even when they get tired of working on their regressions or of calibrating their models.

The rational riddles research program is fascinating in more aspects than just in its sophistication and inventiveness. I want to point out two of them that relate to the scientific value of the solution and its availability and testability.

\subsection{Value of Solution}

The solution to a rational riddle has a peculiar status among answers that economic science can offer. Ironically, despite all the impeccable economic logic of these solutions, they are not likely to be very valuable for understanding how our world works. This is because each and every such solution (assuming it is formally correct) can turn out to be empirically either correct or incorrect.

If the solution is correct it means people whose behavior was examined by economists indeed do behave the way economists hypothesized. This may appear as a great achievement. In a way, it is and it surely demonstrates the ingeniousness and intuition of the economist who made that discovery. But that discovery is certainly not as new as one would assume real discovery to be. And this is because, as follows from the premise that it is empirically correct solution to the riddle, the economic logic of that behavior (as a profitmaximizing strategy) must have been known all along to those who have behaved like that and whose behavior only caught attention of a curious economist. (It should be clear that if agents were ignorant of the logic, it could not then be claimed that they are acting according to it.) The practical usefulness of such solution then may not extend much beyond economists' mental training or a signal of an economist's capability. 


\section{Ekonomie}

On the other hand, if the proposed solution is not empirically correct, it means that people do not behave the way they do for the reason economists propose. Despite being empirically inapplicable its usefulness may be just about the same as the usefulness of the correct solutions (logical exercise and brain-teasing).

Either way, empirically correct but not new, or just empirically incorrect, the same conclusion applies: what these economists produce is an intellectual feat that adds very little to the knowledge about how real-world people behave. (There is one important way in which this conclusion may be subverted: if economists - instead of asking why people do what they do - accepted from the very beginning that people may act on irrational beliefs about means and undertook to explain why people's behavior still survives. In this setup, economists might indeed discover how people's behavior is in fact effective in bringing about the desired end, even if people are unaware of it. People may of course imitate behavior they found successful without knowing why it works, or, more often, may have erroneous beliefs about why it works. Evolution - the natural selection (survival) on the market - will promote those who imitate such behavior and punish those who deviate from it [1, pp. 217-220], and economists may in such cases make truly valuable contribution by explaining why the mechanism really works.)

\subsection{Availability of a Solution}

Another peculiar feature of a rational riddle solution is the relative ease with which it can be verified, tested and even discovered in the first place.

When tackling the riddles economists are trying to discover the strategy of some decisionmakers. When they produce a solution, when they think they did puzzle out the alleged paradox, one would expect them to doublecheck that hypothesis with the decision-makers to acknowledge its correctness. If empirically correct, they would receive an affirmative answer (something like "yes, you have guessed it!"-type of a response), if not they would go ahead guessing.

After all, asking the very people whose behavior is the subject of examination whether the explanation for their behavior is correct, is surely the easiest way to find out just how relevant and applicable that explanation is. Yet, the economists do not seem to be much interested in taking that step. Instead, they submit the explanation as independent from what the decision-makers think and many of those alleged paradoxes are considered by economists as unresolved and waiting for still more ingenious solution. This is roughly what Deirdre McCloskey calls "Samuelsonian Vice" [13, pp. 63-69].

In fact, as was pointed out above, as long as the riddles have rational solutions, there is no reason to rely on economic scientists to come up with them, no matter how tricky and ingenious it may be. It must already exist in the heads of those rational decision-makers themselves - they are behaving in this way now. If economists have hard times revealing what it is or keep arguing about merits of their respective explanations, all they would need to do to settle the argument is to ask the people who do know.

This is a fundamentally different scientific problem than the one tackled by natural scientists. They never enjoy the possibility of actually asking the subjects of their inquiry about why they behave the way they do. Economists, on the other hand, avid to understand people's behavior, almost always could. Trying to discover the answer prior to, and independently of, asking the people whose behavior economists study could certainly constitute an interesting discipline in a "best economist contest", but may fail to contribute much to understanding the true reality. (It is true that people may not always speak truth, and may even be motivated not to reveal the truth to protect their business technology. The phenomena described as rational riddles are so widespread though that it would be fantastic to assume that an attempt of all its practitioners to keep it secret would ever work, much less for so long. Unbelievable as it is, it is precisely this scenario that is implied by the economists' neglect of contrasting their ideas to what people say.)

\section{Riddles Solved}

To illustrate and substantiate such claims I think it necessary to support it by looking at some rational explanations of seemingly irrational behavior. I have chosen three popular economic riddles and roughly mapped the solutions to them suggested in economic literature. 
All cases have to do with pricing. This is because there is a common prejudice that as business decisions they are most likely to be undertaken rationally as a means to profit maximization. Therefore they constitute cases where it makes the best sense on the part of economists to search for rational explanations.

\subsection{Popcorn Overpricing}

Some economists keep being intrigued by the fact that popcorn costs allegedly too much in movie theatres. This is because the profit maximization strategy in this situation would under conventional assumptions entail just marginal cost pricing for popcorn combined with an accordingly higher entrance fee. (The conventional assumptions include e.g. identical costumers' preferences [11, p. 369].) The authors then look for reasons why selling popcorn so dear actually secures higher profits than marginal cost pricing of the conventional theory.

All explanations of this deviation from the expected behavior revolve round price discrimination. They argue there is a positive correlation between preference for popcorn and willingness to pay for the entertainment in the theater (i.e. for the bundle of watching the movies and consumption of snacks from concession stands). Examples of such reasoning are provided by e. g. Friedman [6, pp. 51-53] or Landsburg [10, pp. 159-161]. In order to charge more to those who value coming to the theatre more, it is found natural that price of popcorn (soda or other snacks) will be raised above marginal cost while the entrance fee lowered in order to attract those, who would not otherwise come. (More formal analysis is provided by Luis Locay and Alvaro Rodriguez [12, pp. 959-960].) Thus, the puzzling high price of popcorn is after all a rational profit-maximization.

The one explanation the authors expressly deny happens to be the one routinely offered by lay people when confronted with this question: that the theatre owner just takes advantage of his monopoly on the popcorn market within the theater. But theatre owners are lay people, and there seems nothing fantastic about them doing it for the same - erroneous - reason as other people assume owners to behave like that.

\subsection{9-pricing}

One of the price strategies that still attracts some attention among economists is the practice of charging prices ending in 9: $\$ 5.99$ instead of $\$ 6.00, \$ 79$ instead of $\$ 80$ or similar. (While this riddle also appears in Landsburg's popular book [10, pp. 10-19], it was inaugurated in the hall of riddles as early as 1936 [7]. Anecdotally, such practice is supposed to have originated with a Czech shoe producer Tomáš Bata. This may have been local invention or introduction, but, generally, these "just-below prices" first appeared in 19th century after the invention of a cash register.) Higher frequency of 9's at the end of prices is surely suspect in a world of conventional rational pricing models.

What then could, according to some economists, make businesses choose this pattern of pricing over more conventional - and in rational terms explainable - pricing strategies? One reason, presented by Landsburg, is an elimination of the agency problem: employees are less likely not to register sales if the price is such as to require giving change back to the customer [10, pp. 15-16]. Other authors speculate e.g. about quality signaling properties of the 9-ending versus 0 -ending prices [16].

The reason for economists being puzzled here is their unwillingness to accept the manon-the-street explanation: that 9-ending prices are perceived by consumers as lower than they really are, which is why they buy substantially higher quantities. While it is surely surprising and hard to square with plain rationality that people would routinely zero in on the numbers to the left from the 9 and round the price downward, we should not lose sight of the fact that customers are men-on-the-street. And if this is what consumers do, they may indeed be doing it for precisely this unbelievable reason. (In fact, studies of consumer choice admit both the possibility of this behavior on the part of consumers [14], and the possibility of illusion on the part of businesses about the extent to which consumers indeed behave that way, thus indicating an error on the business side [2].)

\subsection{Ticket Underpricing}

Perhaps the most compelling and important of all riddles are instances of sub-equilibrium prices implying shortages and queues on some markets. This purposeful non-price rationing takes place for instance in selling admission 


\section{Ekonomie}

tickets. Why do theater owners, concert producers and others charge sometimes so little despite the fact that there is an excess demand and it seems they could increase the price without selling less and thus increase their profits? Here is what economists submit as general solutions to the seller-induced excess demand puzzle.

Perhaps most simply, there is a conjecture that consumers may perceive a certain limit of the price beyond which they would consider the price "unfair" [8]. Sellers may then be afraid of crossing such threshold, and choose to live with the queues.

Or, it has been proposed that creating an excess demand may cause a "buying frenzy" with consumers being driven to purchase sooner than they otherwise would. This means that consumers make less informed purchasing decisions and that the producer can charge higher price to people who would normally postpone their purchase to become more informed [5].

Further, it has been asserted that, in some cases, inducing an excess demand may be a way to influence the composition of the audience. As the existence of complementary goods to attending an event varies across the audience, the seller may find it profitable to trade off lower receipts from the box office for higher sales of complementary goods (CD's, videos, T-shirts and other paraphernalia). Provided the attendees who tend to buy more complementary goods than others are those who are also willing to incur extra cost of getting hold of the tickets (standing in line, buying from scalpers etc.), selling at lowerthan-market-clearing price may be a profitable strategy. (This argument is attributed to Kenneth McLaughlin [10, p. 13].)

Finally, and perhaps most convolutedly, it is suggested that in case of some goods, the individual demand is dependent on the total quantity demanded on the market. This is said to lead to a possibility of an upward sloping demand (within certain quantities) and a profitmaximizing equilibrium at a price that generates excess demand. Such equilibrium is unstable, however, and may be upset by a price hike. In such case, the reduction of quantity demanded might cause the individual demands to falter and the market to revert to a standard equilibrium at both lower price and lower quantity and, consequently, lower the level of profit [3].

An implicit assumption behind all these rationalizations is that, surely, the sellers have good, profit-maximizing reasons not to raise prices, not as the conventional wisdom would have it: that lines are a consequence of the product to be of limited availability. But would it be impossible for the ticket sellers to share such conventional wisdom?

\section{Solutions Tested}

Some of the above explanations may have their merits and presumably may be applicable as solutions to the particular riddles, even if on a limited scale: fairness constraints relate mostly to situations of price gouging; buying frenzies are restricted to new products; complementary goods may be important in case of some concerts or sports games, but are hardly present everywhere where there are lines. Many of them, however, are based on such complex economic reasoning that there seems to be some grounds for doubting their real-world plausibility. It would be fair then to put these solutions to test, particularly if the test is easier than it seems - all that needs to be done to solve these mysteries once and for all is to go and ask the people whose behavior economists speculate about.

Now, surprisingly, this is not happening. Economists keep trying to construct theoretical explanations, but nobody seems to have gone to movie theater owners to ask them to what degree they consider their customers different and what they thought of the correlation between willingness to pay for seeing movies and consumption of popcorn. Has someone asked the sellers what they signal with the "justbelow" prices they charge? Has anybody gone to the Becker's Palo Alto sea food restaurant and confirmed that the owner indeed assumes the individual quantity of his products demanded depends on the aggregate quantity demanded? (There were studies asking the sellers whether they charge such prices, but, astonishingly, not why. In fact, Stiving starts by citing a multitude of studies from 1954 till 1997 that establish the fact that such prices are indeed charged by asking the company managers [16, p. 1618], and then spends his whole article on hypothesizing when and why they do so. Landsburg, on the other hand, 
suggests to test his idea about agency problem by testing the hypothesis that "99-cent pricing should be less common in stores where the owners work the cash register" [10, p. 16].)

In order to close this empirical void, we focused on the problem of ticket underpricing, and interviewed head managers of three performance theaters in Prague. All of the theatres are infamous for lines at their box offices, ranging from single hours to overnight waiting time. We asked all of them about the causes of the lines, about the influence of price on their profit and reasons for not increasing the price.

The survey was conducted in November and December 2007 as interviews in person (with one exception). Besides three theatres it included other businesses as well: 2 restaurants, 2 hair studios, 1 ice-hockey club and 1 concert producer (interviewed over phone). The common denominator of all the non-theatre cases was that the lines seemed to be a product of imperfect foresight and risk aversion and would thus not be classed as rational riddles. For this reason I do not reproduce the interviews here and limit myself to theatres only.

\subsection{Theatre $\mathrm{A}$}

In the first theatre $(A)$, the management perceives lines as a problem and repeatedly it tries to address them. In fact, the head manager admitted that had she been a regular theatre visitor, she would have never attended any of the performances there as she hated standing in lines (emphasis added).

The answer to a straightforward question about the causes of lines was, unwaveringly, that the number of seats is too small to accommodate all the people who would like to come. The way they have dealt with the lines was to a) keep their box office as the only ticket distribution channel, and b) limit the number of tickets an individual is allowed to purchase to 4 . Both a) and b) were designed to prevent second-hand dealings with purchased tickets, which was expected to make sure "the performance would be attended by as many people who want to come as possible". As this number can hardly change due to the fixed number of seats, she might have possibly meant that the audience composition would be affected by the price. Indeed, later in the interview she briefly mentions they "are not interested in snobbish audience."
Only when explicitly cued, the head manager reluctantly admitted the possible role of ticket prices but pointed out immediately that people could not afford it then. She commended the fact people had never complained about prices and thought that raising the ticket prices would force their customers to limit the number of tickets they buy in their lifetime. And this, as she emphasized, was not the goal of the theater.

\subsection{Theatre B}

In the second theater (B), too, the manager has a "simple" explanation for the lines: the number of people interested in coming is greater than the theater capacity and "people have to, naturally, come ahead of time". He thought this system is just but restrictive at the same time as it relies on limits on purchases and does not allow reservations, which, he admitted, is particularly vexing for people outside of Prague. They are not aware of, and thus are not concerned about, second hand dealings with tickets. When asked what they would do if they knew it was happening, the head manager pointed to possible way of increasing the transparency such as "informing the people about the number of tickets".

The question of ticket prices had to be brought up explicitly by the interviewer. The answer was uncertain, indicative of no prior consideration and of confusion between all possible effects. Prices, on the one hand, he asserted, "would have no effect on the number of people who buy the tickets". This should not be too surprising as the number of seats is fixed. What he probably meant was that the quantity demanded (the number of people who want to buy) would not be affected.) Even if they had an effect, he went on, people would resent seeing prices increased. On the other hand, almost immediately, he added there might be some room for price increases. At the end, the low prices (and the lines) were rationalized as a means for securing a "grassroot" composition of the audience.

\subsection{Theatre $\mathrm{C}$}

Lastly, the interview with the operations director of the third theater $(C)$ had almost an identical plot. She claimed they have lines because people like what they do and their auditorium space is limited. When maneuvered to the 


\section{Ekonomie}

possible role of prices, she thought it was of secondary importance. On the other hand, she revealed that they had increased their prices and do so every year, and admitted they try to reflect the demand for their performances. On yet another hand, though, she added that the price increases were necessary due to the operation cost and that the growing demand was something that enabled them to pass the cost to the audience, more than being a motivation for price increases. Finally, she contradicted this by admitting that e.g. before Christmas they offer gift tickets at higher prices and charge higher prices for performances notorious for the lines. She noted that the lines have been reduced by "almost a half" of their previous lengths, and attributes this mainly to the price increases, possibly supported by a system of internet reservations.

It would be wholly improper to consider this micro-survey as robustly exploding the whole riddle-solution-research program. Its results are, however, still of interest as they do not exactly paint a picture of the theatre management doing something even remotely as sophisticated as the economic theorists suggest. And it is not the lack of rigorous economic thinking on the part of the theater managers and their failure to use the very language and concepts of professional economists. It is that the interviews reveal precisely the type of economic thinking economists rule out before they start their thinking about the problem, which is why they not only end up, but already start working in, a different world.

No respondents on their own even linked the existence of lines with the prices, much less with prices being "too low". Instead, all of them thought it had to with scarcity, as if other things in the world besides theater tickets were not scarce. Even when prompted about the prices, the immediate reaction was - with the possible exception of $\mathrm{C}$ - that this would not work because people would not be able to afford it, as if the low price made the tickets somehow generally more available. (Given the fact that theater $\mathrm{C}$ showed substantially less puzzling behavior - they do adjust prices according to demand, and effectively manage to shorten their lines - it may be of interest to mention that the manager of $\mathrm{C}$ was a university graduate with some economic education. The other managers (those of $A$ and $B$ ) were non- business, arts educated persons. This would coincide with findings cited by Bryan Caplan on the - quite unsurprising - negative correlation between economic education and the level of biases about economics [4, pp. 50-93]).

Some of the other responses seduce one to rational interpretation: e.g. the idea that people would resent price increases may sound like Kahneman et al. and their concept of fairness constraint [8]. Or, the influence of price on the audience composition rings a somewhat rational bell. However, neither of these is a sufficient reason for not raising the prices and both are much more likely to be relevant under alternative - non-profit-maximization - schemes. (The theater managers may know that buyers will resent the price hikes, and still it may be more profitable to do so. Similarly, even if the theater managers and ensemble prefer the sort of audience made of people who can put up with standing in the line overnight, but still it may be more profitable to have higher prices and "worse" audience. In these situations, their decision not to raise prices will then be economic only as long as their utility functions include feel-good arguments such as public approval, or fond relations with the audience.)

As will be recalled, however, the economists' solutions to riddles are provided as rationalizations of lines under profit-maximization assumption - otherwise the explanations would be considered as trivial imputation of behavior (means) right into the goals (ends). Either way, truly sophisticated solutions like the one offered by Becker [3] seem somewhat irrelevant in the context of the business thinking the interviews attempt to document. Unless, of course, one is to argue that the managers did not want to disclose their real strategies, and just "played stupid" instead. Unlikely as it is, it brings me finally to the economics of being stupid.

\section{When the Stupid Comes In}

We have seen above that there is in fact an easy way to test the empirical relevance of economists' solution to rational riddles: by asking the very people whose motives they have tried to second-guess. We also saw that such surveys are unbelievably rare if not nonexistent. But even if these surveys were undertaken, they would at best produce a logic that was already known and practiced, even if not formally described on pages of an 
economic journal. That might not be exactly the best use of economists' intellectual capacity, but at least it would prove the empirical power of the discipline (and, presumably, made some economists prouder of themselves).

When, on the other hand, the solutions proposed by economists are found empirically irrelevant, it may only mean one of the following: a) no economists correctly guessed what businesses are up to (the game may proceed), or b) no such further solution exists as the puzzling behavior is indeed and simply a product of irrational thinking the economists refused to accept in the first place. Its triviality notwithstanding, this eventuality may be empirically very relevant and important.

If economists choose to banish the possibility of irrationality, their understanding of what is going on is impaired. What looks like an outwitting game with no social consequence is just a tip of the iceberg - the economists' determination to insist on rationality may create imaginary puzzles where there are none and thus divert their scarce intellectual resources from areas where they are more needed.

One area that was hit particularly hard by resistance to irrationality is the economics of policy-making. Bryan Caplan's book, compiling and wrapping up his research project of the past decade or so [4], shows quite convincingly that attempts to explain persistence of foolish public have systematically shunned the possibility of the electorate being mistaken in understating the impact of the policies. Political process, perverted as it may be, does not explain away all the public policy foolishness. If democracy produced policy that people really liked, it would have been even more foolish than it is. Caplan points out how much the ideas of the public are systematically biased compared to what economists think. Indeed, my findings in the theater survey - the lack of appreciation of the role of prices - tallies directly with the biases he was able to identify. He thus shows that the folly of the electorate may be the missing piece in the puzzle. That the attempts of standard public choice theory to account for persistence of bad policies have been failing and have produced convoluted and useless theoretical work precisely because economists in the past century - unlike some of the century before that - turned a blind eye to the possibility of human folly. As Caplan concludes his book:
Social science has pursued many blind alleys - and ignored many promising ones out of misguided insistence that every model be a "story without fools," even in areas like politics where folly is central. A proverb tells us that "a wise man learns more from a fool than a fool learns from a wise man." By closing their eyes to fools and folly, the wise men of social science have artificially hobbled the advance of their own learning. [4, p. 209]

\section{Conclusion}

The purpose of this article was two-fold.

First, I wanted to bring attention to two strange features of economists' research program. When economists speculate about why people's behavior is rational (which is what they do when cracking the rational riddles), the result of such scientific effort - all its sophistication, ingeniousness and formal impeccability notwithstanding - is either correct, but not new (i.e. it has been known before to the examined people), or simply wrong in the sense that the solution does not apply (i.e. it is empirically empty). Either way, the significance of such science seems compelling bit limited. Moreover, this is just as strange as the way through which economists typically try to test the empirical validity of their results. Testing hypotheses implied by the results can, of course, shed much light on that question, but since their results relate essentially to a question of why people do what they do, it is the examined people who can settle the issue. While data can talk, so can the people.

Second, I suggest economists may be somewhat uneconomical in their research efforts. By insisting on models with rational actors only, they may embark on a vacuous rational riddles research project in the first place. And through their isolation from the people they examine, they fail to find out that in many cases the rational riddle solution does not exist, and that the behavior they speculate about is a product of confusion and folly, that it is simply irrational.

This is in no way a plea for discarding the rationality assumption in economics. It is only a plea for remembering that it is an assumption that may just as well not be met. By heeding it, economists can economize on their scarce research resources, and perhaps devote more 


\section{Ekonomie}

of them to, and do an even better job in, areas where such assumption holds.

The author would like to thank Josef Montag for comments and administrating and processing the micro survey, and to David Lipka and Ed Stringham for valuable comments on previous versions of the text. Others I choose to leave unmentioned lest someone is left out. The usual caveat applies.

\section{References}

[1] ALCHIAN, A.A. Uncertainty, Evolution, and Economic Theory. The Journal of Political Economy. 1950, Vol. 58, Iss. 3. ISSN 0022-3808.

[2] ANDRESON, E.T., SIMESTER, D.I. Effects of $\$ 9$ Price Endings on Retail Sales: Evidence from Field Experiments. Quantitative Marketing and Economics. 2003, Vol. 1, Iss. 1, pp. 93-110. ISSN 1570-7156.

[3] BECKER, G.S. A Note on Restaurant Pricing and Other Examples of Social Influences on Prices. The Journal of Political Economy. 1991, Vol. 99, Iss. 5, pp. 1109-1016. ISSN 0022-3808.

[4] CAPLAN, B. The Myth of Rational Voter: Why Democracies Choose Bad Policies. Princeton: Princeton University Press, 2007. ISBN 978-0-691-129-426.

[5] DeGRABA, P. Buying Frenzies and SellerInduced Excess Demand. RAND Journal of Economics. 1995, Vol. 26, Iss. 2, pp. 331-342. ISSN 1756-2171.

[6] FRIEDMAN, D. Hidden Order: The Economics of Everyday Life. New York: HarperCollins Publishers, 1997. ISBN 978-0-887-3088-57.

[7] GINZBERG, E. Customary Prices. The American Economic Review. 1936, Vol. 26, Iss. 2, pp. 296. ISSN 0002-8282.

[8] KAHNEMAN, D., KNETSCH, J.L., THALER, R. Fairness as a Constraint on Profit Seeking: Entitlements in the Market. The American Economic Review. 1986, Vol. 76, Iss. 4, pp. 728-741. ISSN 0002-8282.
[9] KAHNEMAN, D. New challenges to the rationality assumption. Journal of Institutional and Theoretical Economics (JITE)/Zeitschrift für die gesamte Staatswissenschaft. 1994, Vol. 150, Iss. 1, pp. 18-36. ISSN 0932-4569.

[10] LANDSBURG, S.E. The Armchair Economist: Economics and Everyday Life. New York: The Free Press, 1993. ISBN 0-02-917776-6.

[11] LANDSBURG, S.E. Price Theory and Applications. Cincinnati: South-Western (Thomson Learning), 2002. ISBN 0-324-05979-5.

[12] LOCAY, L., RODRIGUEZ, A. Price Discrimination in Competitive Markets. Journal of Political Economy. 1992, Vol. 100, Iss. 5, pp. 954-965. ISSN 0022-3808.

[13] McCLOSKEY, D.N. The Vices of Economists - The Virtues of the Bourgeoisie. Amsterdam: Amsterdam University Press, 1996. ISBN 978-9-053-562-444.

[14] SCHINDLER, R.M., KIRBY, P.N. Patterns of Rightmost Digits Used in Advertised Prices: Implications for Nine-Ending Effects. Journal of Consumer Research. 1997, Vol. 24, Iss. 2, pp. 192-201. ISSN 0093-5301.

[15] SEN, A.K. Rational fools: A critique of the behavioral foundations of economic theory. Philosophy \& Public Affairs. 1977, Vol. 6, Iss. 4, pp. 317-344. ISSN 0048-3915.

[16] STIVING, M. Price-Endings When Prices Signal Quality. Management Science. 2000, Vol. 46, Iss. 12, pp. 1617-1629. ISSN 0025-1909.

\footnotetext{
Dan Št’astný

Jan Evangelista Purkyně University in Ústí nad Labem

Faculty of Social and Economic Studies Department of Economics Daniel.Stastny@ujep.cz
} 


\section{Abstract}

\section{THE ECONOMICS OF BEING STUPID: A NOTE ON (IR)RATIONALITY IN ECONOMICS}

\section{Dan Št’astný}

Economists' habit of imputing rational motives to all human behavior gives rise to 'rational riddles': rational explanations for seemingly irrational behavior. In the article I argue that economists' solutions to these riddles are, despite their sophistication, of limited scientific value as they describe mechanisms that are never both new and correct: they may be empirically correct but not new as these mechanisms have been practiced (hence known) by some people before; or they are genuinely new (previously unknown to anybody), but empirically wrong as they fail to account for the real reasons of observed behavior. I further show that the hypothesized solutions to the riddles could be easily tested by consulting the people whose behavior is examined, and point to the strange lack of economists' efforts to do so. Finally I present results of a micro survey relating to one such rational riddle: ticket underpricing (why prices of tickets for various events do not adjust to eliminate the excess demand). By interviewing managers of theatres known to sell tickets at prices that create lines, I present some evidence showing that it is much easier to explain the observed behavior in terms of plain ignorance of some elementary economic principles or facts rather than in terms of some economic sophistication on the part of the managers. No interviewees, for example, explicitly related the existence of lines to ticket underpricing, and some actually denied any link there even if prompted. I conclude by pointing to the real cost to the economic profession stemming from its decision to ignore the possibility of irrationality in economists' research program.

Key Words: Irrationality, rational riddles, pricing, lines, theatres.

JEL Classification: A11, B41.

DOI: 10.15240/tul/001/2014-2-001 